\title{
Human Cysticercosis: A Probable Case of Cerebral Cysticercosis with Generalized Subcutaneous Nodular Lesions
}

\author{
Z. ALI-KHAN, S.CHAYASIRISOBHON and M. AUBE
}

SUMMARY: $A$ case is reported in Montreal of human cysticercosis in a 44year-old man who emigrated from Italy in 1956. Numerous subcutaneous nodules were found throughout his body. X-ray of his thighs and chest showed oblong calcific densities measuring $1 \times 0.5 \mathrm{~cm}$ in size. Examination of an excised nodule from the right biceps revealed a cysticercus larva

RÉSUME: Cysticercose humaine: un cas probable de cysticercose cérébrale avec des lésions modulaires sous-cutanées généralisées.

Nous rapportons un cas, à Montréal, de cysticercose humaine chez un homme de 44 ans émigré d'Italie depuis 1956. Nous avons trouvé de nombreux nodules souscutanés dans toutes les parties du corps. Des radiographies de ses cuisses et thorax montrent des densités calcifiées de forme oblonque et mesurant $l \times 0.5 \mathrm{~cm}$. morphologically similar to Cysticercus cellulosae although the scolex lacked hooks. On the basis of the intensity of infection, focal and generalized epileptic seizures, changes in the CSF, and well demarcated lucencies observed in brain scan, cerebral cysticercosis was considered the most likely diagnosis.

L'examen d'un de ces nodules provenant du biceps droit a montré une larve de cysticercus semblable morphologiquement au cysticercus cellulosae, même si le scolex n'avait pas de crochets. Sur la base de l'intensité de l'infection, la présence de crises épileptiques focales, les modifications du LCR et la présence de zones translucides bien localisées à la tomodensitométrie cérébrale, nous croyons que le diagnostic de cysticercose cérébrale est le plus probable.
From the Clinical Parasitology Laboratory Department of Microbiology and Immunology and the Department of Neurology, The Montreal Neurological Institute, McGill University, Montréal, Qué.

Reprint requests to: Dr. Z. Ali-Khan, Dept, of Microbiology and Immunology, McGill University, 3775 University St., Montréal, Québec, H3A 2B4 Canada.

\section{INTRODUCTION}

Human cysticercosis caused by the larvae of Taenia solium (pork tapeworm) has a world-wide distribution, occurring frequently in parts of Central and South America, Africa, Eastern Europe, Mediterranean countries, and the Far East. The incidence of this infection is especially high in low socio-economic communities with poor standards of hygiene (Dix on and Lipscomb, 1961; Powell et al., 1966; Marcial-Rojas, 1971). Cysticercosis results from the ingestion of ova either by man or pig. The pig is the intermediate host harboring Cysticercus cellulosae in the muscle and thereby serving as the source of the adult parasite to man.

Clinical cysticercosis (cerebral, intraocular, and cardiac) in man depends upon the number of cysticerci, their anatomical location, and integrity in the tissue; degenerating larvae incite severe inflammatory and necrotic changes in the surrounding host tissue. Cerebral cysticercosis may be clinically silent or may take a severe clinical course with at least three manifestations: intracranial hypertension from meningeal involvement, convulsion, and mental disorder from parenchymal involvement (Dixon and Lipscomb, 1961; MarcialRojas, 1971; Arseni and Samitca, 1957). Subcutaneous cysticercosis, on the other hand, is benign in nature and is by far the most common cause of multiple subcutaneous nodular lesions.

We present a case of cysticercosis suggestive of cerebral involvement together with the histological features of the larva in a biopsied subcutaneous nodule. The present case is the second 
report of human cerebral cysticercosis from Canada (Owen and Lenczner, 1956).

\section{CASE HISTORY}

A 44-year-old right handed male, who had emigrated from Italy in 1956, was admitted in November 1958 to the Royal Victoria Hospital Clinic because of hard subcutaneous lumps on both his arms and shoulders. Two biopsies were taken from nodules overlying the right biceps muscle. Histological preparations revealed a cysticercus larva. The patient admitted occasionally nibbling at raw pork or beef when his wife made sausages. He denied any episodes of fever, generalized muscle tenderness, or diarrhea before or after the onset of his skin problem.

In 1965 the patient experienced an episode of sudden turning of his head and eyes to the right side which lasted for several minutes. In 1976 he suddenly felt confused, his eyes and head turned to the right, and his right upper and lower extremities began shaking. He fell down and became unconscious. He was brought to a hospital and was treated with Dilantin $300 \mathrm{mg}$ per day. Since this last seizure, the patient has noted occasional squeezing bifrontal and bitemporal headaches lasting for a few hours at a time and also trouble in pronouncing words. On admission to the Montreal Neurological Hospital all his vital and neurological signs were normal except for round, firm, non-tender, subcutaneous nodules approximately $0.5 \mathrm{x}$ $1.0 \mathrm{~cm}$ in size found over both biceps, shoulders, chest, and thigh.

\section{LABORATORY INVESTIGATION}

The urinalysis, hemogram, SMAC, electrocardiogram, and VDRL were normal. Serum thyroxin $T_{4} \quad(6.4$ $\mu \mathrm{g} / 100 \mathrm{ml}$ ) and $\mathrm{T}_{3}$ resin uptake $(41.5 \%)$ and serum protein values were normal. Stool examinations for occult blood and parasites were negative. The indirect hemagglutination test using Echinococcus granulosus antigen gave a titer of 1:128. The IHA test for trichinosis was negative.

\section{X-RAY FINDINGS}

$X$-ray of thigh and chest showed numerous oblong well demarcated calcific densities measuring approximately $1 \times 0.5 \mathrm{~cm}$ (Fig. 1). The skull

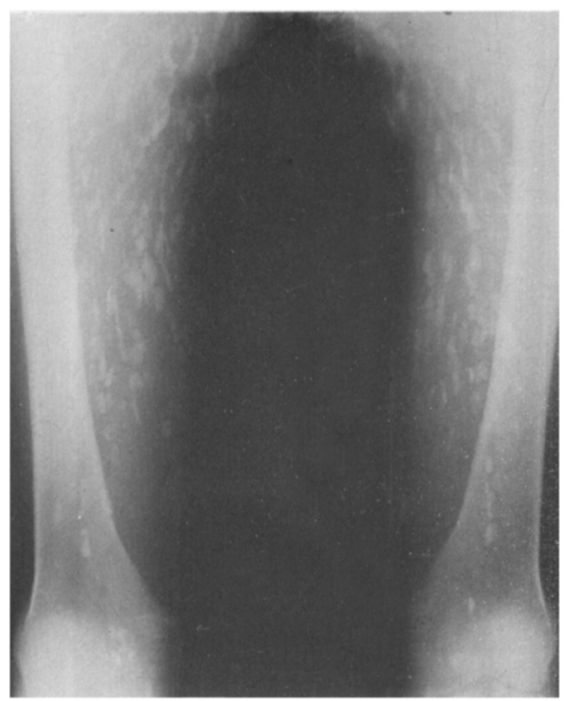

Figure $I$ - X-ray of the thigh muscle showing numerous oblong well demarcated calcific densities representing cysticercus larvae.

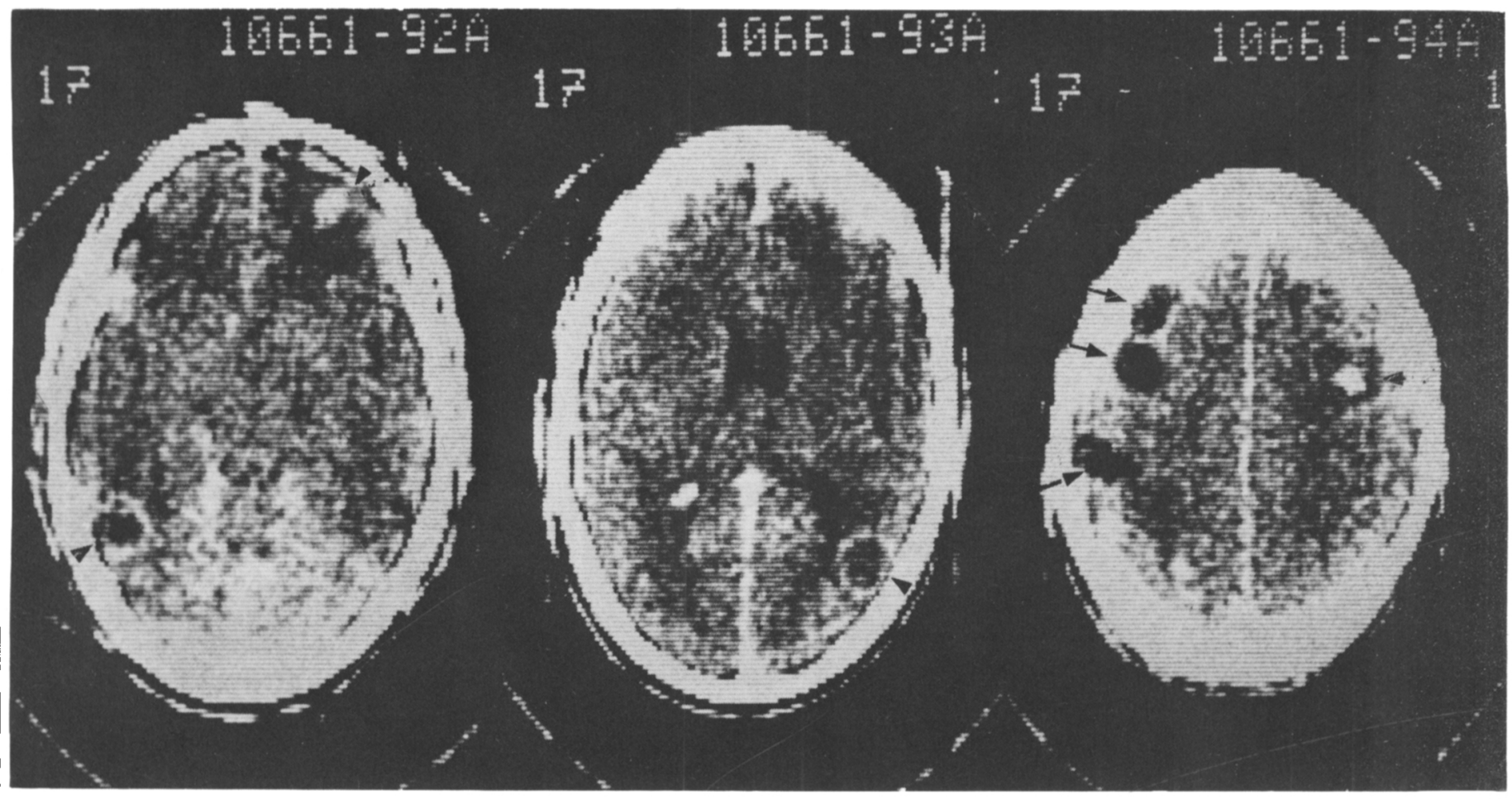

Figure 2-A CT scan with contrast medium injection showing the areas of vascular enhancement (arrowheads) with posterior aspect of the inferior gyrus and right central region. The well demarcated lucencies (arrow) are seen in the left fronto-centro-parietal regions. 
film revealed no intracranial calcification but an enlarged sella turcica which was also confirmed by a computerized tomogram (CT). The enlarged sella was probably due to an intrasellar lesion or in relation to an empty sella.

\section{NEUROLOGICAL EXAMINATION}

Electroencephalogram gave evidence of a mild intermittent paroxysmal disturbance of cerebral activity maximal over the frontopolar region. Brain scan was within normal limits. CT scanning with and without infusion showed areas of vascular. enhancement situated in the posterior aspect of the inferior temporal gyric bilaterally, right superior frontal gyrus, and right central region (Fig. 2). The well demarcated lucencies were seen in the left fronto-centro-parietal regions. A lumbar puncture revealed CSF opening pressure of $160 \mathrm{~mm}$ water. The CSF findings were as follows: clear, colorless, 12 lymphocytes per $\mathrm{mm}^{3}$ (normal 0-5) and a few eosinophils, protein $59 \mathrm{mg} \%$ (normal $15-45$ ), glucose $68 \mathrm{mg} \%$ (normal 5080 ), chloride $730 \mathrm{mg} \%$ (normal 700750 ), Lange 4443221100 , IgG $30 \%$ (normal less than 10.5).

\section{THE PARASITE}

Thirteen skipped tissue sections were available for examination; of these only one section passed through the scolex (Fig. 3) and the rest contained either the whole bladder or portions of the bladder and neck (Fig. 4). The larva, enclosed in thick fibrous host tissue was morphologically intact, oval in outline (size $8.5 \times 4 \mathrm{~mm}$ ), and contained an invaginated acetabulated scolex. The latter lacked hooks and was situated in the highly convoluted spiral canal (Fig. 4). The following histological features, similar to those of Cysticercus cellulosae and C.bovis described previously (Voge, 1963; Powlowski and Schultz, 1972) were present. Cytoplasmic projections (microtriches), less than $2 \mu$ in length, opposed to the host tissue covered much of the acellular outer body layer of the bladder portion of the cysticercus. Under the sunken epidermal cell layer was the parenchymatous tissue which contained calcareous corpuscles, circulatory and probably excretory canals, and muscle bundles.

\section{COMMENTS}

The laboratory examinations, as previously reported (Powell et al, 1966; Dixon and Lipscomb, 1961; Arseni and Samitca, 1957) were of little assistance in establishing the diagnosis of cerebral cysticercosis. However, based upon the patient's previous history and in conjunction with his recent epileptic seizure, the presumptive diagnosis of cerebral cysticercosis was considered most likely. X-ray of the thighs is shown in Fig. 1. The skull films were negative for calcified cysticerci. The CT scan, however, did reveal well demarcated lucencies which were consistent with the presence of lesions or viable cysticerci. The latter when located in the brain are less prone to calcification (Dixon and Lipscomb, 1961). The patient's recent episode of epilepsy may have resulted from degenerative changes in the surrounding brain tissue secondary to the larval death. Epileptic manifestations suggesting cerebral cysticercosis occur in patients without a family history of epilepsy (Powell et al., 1966; Dixon and Smithers, 1934). The seizure patterns are usually focal at onset but change from time to time as the disease progresses. In $92 \%$ of 413 proven cases of cysticercosis, epilepsy was found to be the most dominant clinical feature. The incubation period of mental disorder and other nervous symptoms in this series varied from a few months to 30 years. In the present case, the patient experienced his first generalized epileptic seizure approximately 12 years after the first local seizure.

The histological features of the cysticercus were similar to those of C.cellulosae in several essential details, such as the length of the microtriches ( $2 \mu$ or less in length) and the highly convoluted spiral canal (Voge, 1961; Powlowski and Schultz, 1972). However, the portion of the scolex present in the only section available for examination lacked hooks. Hookless scolex is characteristic of C.bovis (cysticercus larva of Taenia saginata). Powlowski and Schultz (1972) in their review cite at least 12
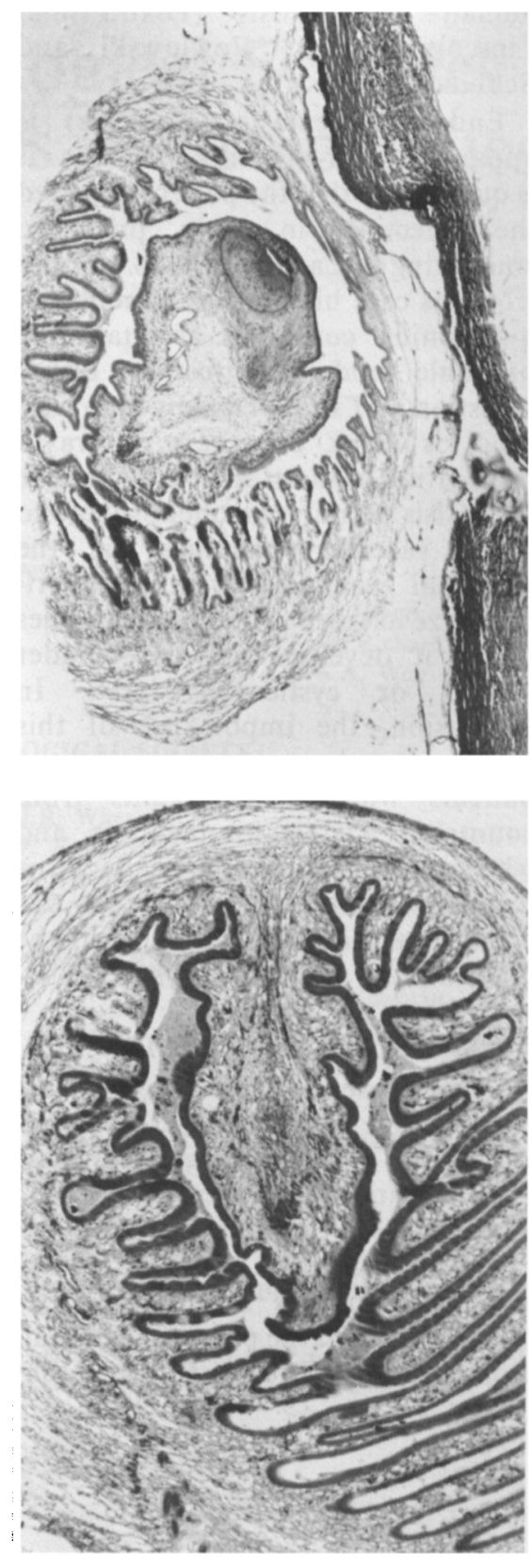

Figure 3, 4- Sections through the scolex and neck region of the cysticercus larva. (3) A portion of the scolex showing muscular acetabulum (sucker) and deep infoldings of the convoluted spiral canal around the scolex, $\mathrm{H} \& \mathrm{E} \times \mathrm{9}$.

(4) Oblique section through the neck region; note the noncellular tegument lining the convoluted spiral canal and the mesenchymal tissue. H \& E x 24.

cases of cysticercosis in man which were claimed to be due to $C$. bovis. It is, however, generally believed that C.cellulosae is the primary cause of 
human cysticercosis (Dixon and Lipscomb, 1961; Powlowski and Schultz, 1972).

Endemic taeniasis (T.solium) is apparently non-existent in Canada. It is quite likely that the patient acquired the infection in Italy prior to emigrating to Canada in 1956. Neither from his case history nor by repeated questioning could we ascertain the probable mode of infection. Either ingestion of T.solium ova by man with food or drink or access of gravid proglottids in the stomach by reverse peristalsis permits the onchosphere to enter vascular channels in the intestinal wall and eventually peripheralize to various organs and tissues where it develops into a "bladder worm" or cysticercus larva. In conclusion, the importance of this report is to draw attention to those patients who are emigrants from countries endemic for taeniasis, and who complain of chronic headache or develop epilepsy. One of the differential diagnoses which should be kept in mind is cerebral cysticercosis.

\section{PROGNOSIS AND TREATMENT}

The present case most likely represents a benign form of parenchymatous cerebral cysticercosis. This type of cysticercosis occurs due to the presence of a few parasites "in the clinically silent areas of the brain" and a limited amount of inflammatory reaction around the parasite (MarcialRojas, 1971). Except for a recent report quoted by Hunter et al. (1976) on the chemotherapy of cysticercosis in which regression of cysticerci and alleviation of patient's symptoms were demonstrated, surgical removal of the parasite if located in the vital organs and endangering patient's life, is the recognized therapeutic procedure.

Choice of drugs for the treatment of T.solium infection is controversial. Both niclosamide (Yomesan) and quinacrine (Atabrine) are effective in killing the adult parasite. Quinacrine, however, is preferred over niclosamide because the latter causes lysis of the tapeworm in the intestine of the host and increases the theoretical possibility of internal autoinfection and generalized cysticercosis (Seftel and Heinz, 1964; de Carneri and Vita, 1973).

\section{ADDENDUM}

Since the preparation of this manuscript two biopsies from cases of generalized cysticercosis due to C.cellulosae, in emigrants from India and Bangladesh were referred to one of us (ZAK) from St. Mary's Hospital and Montreal Children's Hospital, Montreal. The larvae had a hooked scolex and resembled histologically the cysticercus described in the text.

\section{REFERENCES}

ARSENI, C. and SAMITCA, D. C. (1957) Cysticercosis of the brain. British Medical Journal, 2, 494-503.
DIXON, H. B. F. and SMITHERS, D. W. (1934). Epilepsy in cysticercosis (Taenia solium): a study of seventy-one cases. Quarterly Journal of Medicine (New Series), 3, 603-616.

DIXON, H. B. F. and LIPSCOMB, F. M. (1961). Cysticercosis: an analysis and followup of 450 cases. Privy Council, Medical Research Council, Special Report, Series No. 299

HUNTER, G. W., SWARTZWELDER, J. C. and CLYDE, D. F. (1976). Tropical Medicine, pp. 603-608. Saunders, Philadelphia, U.S.A.

MARCIAL-ROJAS, R. A. (1971). Pathology of Protozoal and Helminthic Diseases. pp. 592-617. The Williams and Wilkins Co., Baltimore, U.S.A.

OWEN, T. and LENCZNER, M. (1956). Generalized cysticercosis with cerebral infestations. Canadian Medical Association Journal, 75, 213-216.

PAWLOWSKI, Z. and SCHULTZ, M. G. (1972). Taeniasis and cysticercosis (Taenia saginata) Advances of Parasitology, 10, 269-304.

POWELL, S. J., PROCTOR. E. M., WILMOT, A. J. and MACLEOD, I. N. (1966). Cysticercosis in Africans: a clinical and serological study. Annals of Tropical Medicine and Parasitology, 60, 152-159.

De CARNERI, I. and VITA, G. (1973). Drugs used in Cestode diseases. In: International Encyclopedia of Pharmacology and Therapeutics. pp. 185-213 Pergamon Press, New York, U.S.A.

SEFTEL, H. C. and HEINZ, H. J. (1964). Treatment of human tapeworm infections with Yomesan. Single dose treatment in non-fasting subjects. South-African Medical Journal 38, 263-266.

VOGE, M. (1963). Observations on the structure of cysticerci of Taenia solium and Taenia saginata (Cestode, Taeniidae). Journal of Parasitology, 49, 85-90. 